\title{
REVIEW
}

\author{
David Kühne • Boris Spak • Markus Kästner • Alexander \\ Brosius • Melanie Fiedler
}

\section{Consideration of cyclic hardening and residual stresses in fatigue life calculations with the local strain approach}

Received: 26 October 2020 / Accepted: 26 March 2021 / Published online: 7 June 2021

(C) The Author(s) 2021

\begin{abstract}
The local strain approach (LSA) is an established concept to calculate the fatigue life of mechanical components for failure criterion crack initiation in several fields of engineering. In an elastic static finite element simulation, the critical stress state is detected and forms the basis for an elastic-plastic fatigue calculation with the LSA in a post-processing routine. This paper introduces extension options of the LSA to consider the influences of forming processes on the fatigue life of components.
\end{abstract}

Keywords Fatigue $\cdot$ Local strain approach $\cdot$ Transient material behaviour $\cdot$ Residual stresses $\cdot$ Skew rolling

\section{Introduction}

Forming processes have an influence on the fatigue behaviour of mechanical components, see [28]. Figure 1 shows the influence on the component Wöhler curve for fracture. Comparing the experimental results of unnotched $\left(K_{\mathrm{t}}=1\right)$ and notched $\left(K_{\mathrm{t}}>1\right)$ specimens, the effects of forming processes are clearly visible. A specimen with a higher elastic stress concentration factor $K_{t}$ normally endures less cycles to failure in comparison with a specimen with a smaller $K_{t}$ at the same nominal stress horizon. But due to the forming process, the skew rolled specimen with $K_{\mathrm{t}}=3.6$ (circles) is able to endure a higher number of loading cycles in comparison with a milder notched, annealed specimen with $K_{t}=1.7$ (unfilled triangles). Therefore, the forming process seems to counteract with the notch effect which results in a longer fatigue life, [3]. The forming process of skew rolling leads to three major effects, [11], which explain the influence on the fatigue life: (1) residual stresses are introduced in the structure, (2) strain hardening and (3) improved surface roughness in the rolled area. This paper firstly focuses on the effects of the introduced residual stresses on the fatigue life and neglects the effects of the improvement of surface roughness and strain hardening due to a forming process.

In Trauth et al. [34], a simple model is published in order to approximate the residual stress state due to deep rolling. Near the surface, deep rolling causes high compressive residual stresses which decrease with the surface layer depth. This paper uses a forming simulation considering elastic-plastic material behaviour in order to identify the residual stresses of skew rolling in the notched area and compared to the approach by Trauth et al. for deep rolling.

The impact of forming on the fatigue life of a notched specimen depends on the applied forming process and the used material, see [20], but for deep rolling also on the fatigue process: crack initiation or crack propagation, see [1].

D. Kühne · B. Spak · M. Kästner · A. Brosius · M. Fiedler ( $\varangle)$

Technische Universität Dresden, Dresden, Germany

E-mail: melanie_fiedler@tu-dresden.de

D. Kühne

E-mail: david.kuehne@tu-dresden.de 


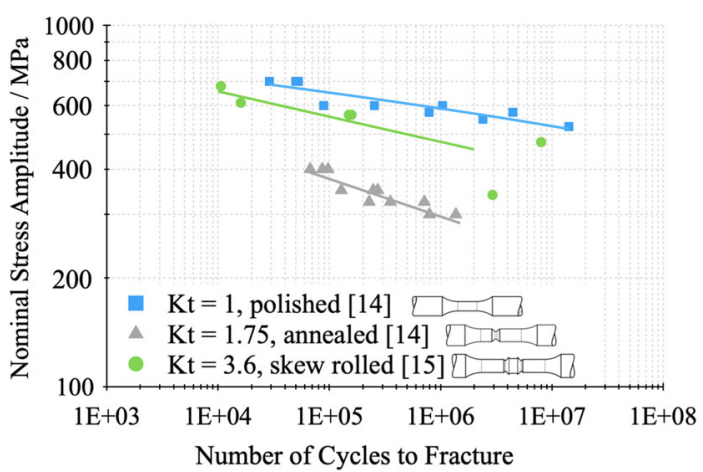

Fig. 1 Influence of skew rolling on the fatigue life of notched specimens $\left(K_{\mathrm{t}}=3.6\right)$ [14], compared to residual stress-free components $\left(K_{\mathrm{t}}=1.7\right.$ and $\left.K_{t}=1.0\right)$ by [13]

In addition to a large number of continuum mechanical damage models (CDM), models based on the theory of critical distance (TCD) [32,36] or on the concept of cyclic plastic zones (CPZ) [33], the local stress concept (LSC), see [29,32], and the local strain approach (LSA), see [6, 8,9], are often used for fatigue life calculations in the industry. In the paper at hand, the fatigue life estimation will focus specifically on crack initiation and calculations with the LSA.

In [14], an approach of an addition to the LSA was published in order to consider the transient material behaviour of an incremental step test (IST).

Here, a new approach is presented, in order to consider transient material behaviour and residual stresses resulting from large plastic strains introduced by manufacturing processes within the LSA. Section 2 gives a short summary of the theory of the LSA, and Sect. 3 shows the additions to the LSA in order to consider transient material behaviour and residual stresses due to the forming process. In Sect. 4, the proposed model is applied to a skew rolled component manufactured from $42 \mathrm{CrMo}$. In Sect. 5, conclusions are drawn from the presented results and an outlook is given to facilitate further research.

\section{Local strain approach (LSA)}

Fatigue failure of ductile materials is caused by cyclic plasticity which therefore has to be considered in fatigue calculation concepts. Within the LSA, the point of failure is assumed on the surface of a notched area. Though it is known that a multiaxial stress state is present in the notched area, an established approach is to use a signed, e.g. von Mises stress. Since elastic-plastic finite element (FE) simulations are impracticable for several thousands of load cycles, a simplified approach is required to determine the elastic-plastic stress-strain state at the critical point from an elastic static FE analysis (FEA).

Figure 2 shows the modules of the LSA as described in [7]. Based on an elastic FEA, the critical point and an elastic stress concentration factor are determined (1). In order to transform the elastic FEA results to elasticplastic material behaviour, a cyclic stabilized stress-strain curve (CSSC) in conjunction with the Neuber's rule is applied (2). For variable amplitude loadings, a simulation of the local elastic-plastic stress-strain path is necessary. The damage effect of each closed hysteresis loop is evaluated using a damage parameter and a damage parameter Wöhler curve (3). For damage accumulation, the Palmgren-Miner rule is used to calculate the fatigue life of the mechanical component for crack initiation (4).

\subsection{Cyclic stabilized material behaviour}

The cyclic stabilized material behaviour is described by the Ramberg-Osgood equation [27]

$$
\varepsilon=\frac{\sigma}{E}+\left(\frac{\sigma}{K^{\prime}}\right)^{1 / n^{\prime}}
$$

with Young's modulus $E$, cyclic hardening coefficient $K^{\prime}$ and cyclic hardening exponent $n^{\prime}$. Equation (1) describes the cyclic material behaviour for initial loading; for unloading/reloading, Masing's law [18] is 


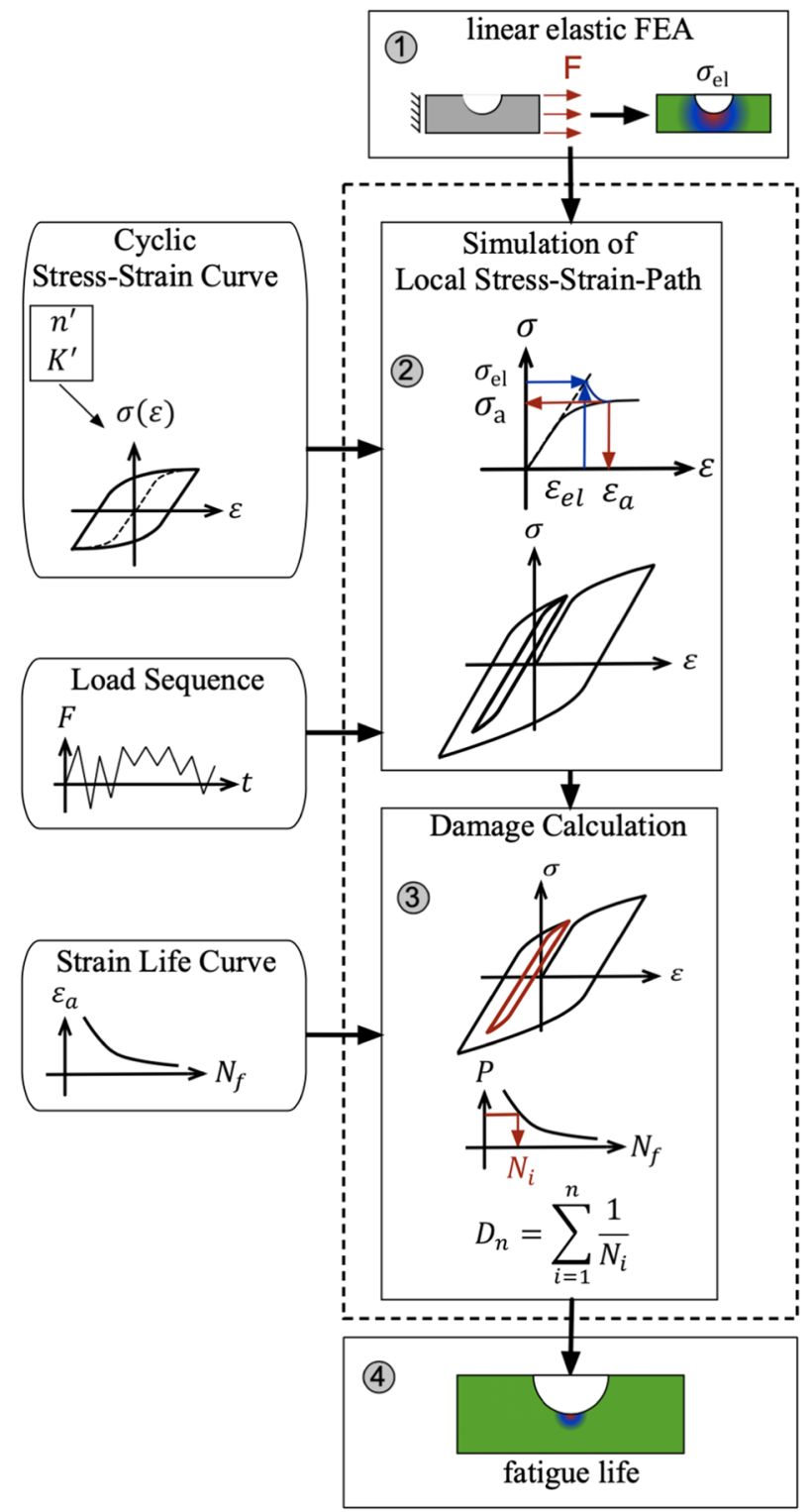

Fig. 2 Flowchart of the local strain approach

applied.

$$
\Delta \varepsilon=\frac{\Delta \sigma}{E}+2\left(\frac{\Delta \sigma}{2 K^{\prime}}\right)^{1 / n^{\prime}} .
$$

Also material memory effects have to be considered within the LSA for variable amplitude loading cases, see Sect. 2.3.

\subsection{Neuber's rule}

The calculated stresses and strains based on the theory of elasticity $\sigma_{\mathrm{el}}$ and $\varepsilon_{\mathrm{el}}$ are reevaluated to local elasticplastic calculated stresses and strains $\sigma_{\mathrm{el}, \mathrm{pl}}$ and $\varepsilon_{\mathrm{el}, \mathrm{pl}}$ using Neuber's rule [22]

$$
\sigma_{\mathrm{el}} \varepsilon_{\mathrm{el}}=\sigma_{\mathrm{el}, \mathrm{el}, \mathrm{pl}} \varepsilon_{\mathrm{el}, \mathrm{el}, \mathrm{pl}} .
$$

Figure 3 shows a schematic diagram of the revaluation. 


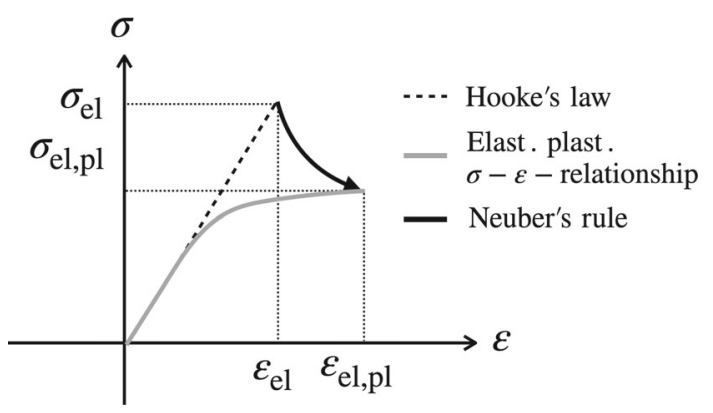

Fig. 3 Application of Neuber's rule

\subsection{Hysteresis counting method (HCM)}

For variable amplitude loading, a hysteresis counting method (HCM) needs to be applied. The HCM algorithm by Clormann and Seeger [4] takes Masing's law and the memory effects into account when simulating the local elastic-plastic stress-strain path. For every closed hysteresis loop, the stresses and strains at the reversal points can be determined and used for damage accumulation. In the LSA, repetitive load sequences are usually run twice with the HCM algorithm, since only the first run follows a different stress-strain path than the subsequent repetitions due to Masing and memory behaviour. Thus, the first run results in a different damage value than the further repetitions. If the second run was simulated, the damage determined from the repetition can be multiplied by a given number of repetitions.

\subsection{Damage parameter}

In the LSA, each hysteresis loop is evaluated by a damage parameter. For a first approach, the damage parameter by Smith, Watson and Topper [31]

$$
P_{\mathrm{SWT}}=\sqrt{\left(\sigma_{a}+\sigma_{m}\right) \cdot \varepsilon_{a} \cdot E}
$$

is used in this paper. The parameter considers the influence of the stress amplitude $\sigma_{a}$, the mean stress $\sigma_{m}$ and the strain amplitude $\varepsilon_{a}$ of each closed hysteresis loop from the hysteresis counting method.

\subsection{Damage parameter Wöhler curve}

From constant amplitude (CA) — testing a strain Wöhler curve described by Manson-Coffin-Morrows approach $[5,16,21]$

$$
\varepsilon_{a}=\frac{\sigma_{\mathrm{f}}^{\prime}}{E} \cdot\left(2 N_{\mathrm{f}}\right)^{b}+\varepsilon_{\mathrm{f}}^{\prime} \cdot\left(2 N_{\mathrm{f}}\right)^{c}
$$

can be derived with material parameters $\sigma_{f}^{\prime}, \varepsilon_{f}^{\prime}, b$ and $c$ and number of cycles to failure $N_{f}$. For a comparison with the damage parameter $P_{\mathrm{SWT}}$, a damage parameter Wöhler curve (P-Wöhler curve)

$$
P_{\mathrm{SWT}}=\sqrt{\sigma_{\mathrm{f}}^{\prime 2} \cdot\left(2 \cdot N_{\mathrm{f}}\right)^{2 b}+\sigma_{\mathrm{f}}^{\prime} \cdot \varepsilon_{\mathrm{f}}^{\prime} \cdot E \cdot\left(2 \cdot N_{\mathrm{f}}\right)^{b+c}}
$$

can be determined from the material parameters of the $\varepsilon$-Wöhler curve. For an alternative formulation of the P-Wöhler curve based on the ultimate tensile strength $R_{m}$, see $[9,35]$.

\subsection{Damage accumulation}

According to the linear damage accumulation hypothesis (Palmgren-Miner rule) $[2,24]$, the total damage is

$$
D=\sum_{i=1}^{n} \frac{1}{N_{\mathrm{f}, i}}
$$

For failure criterion crack initiation, the damage sum is $D=1$. 

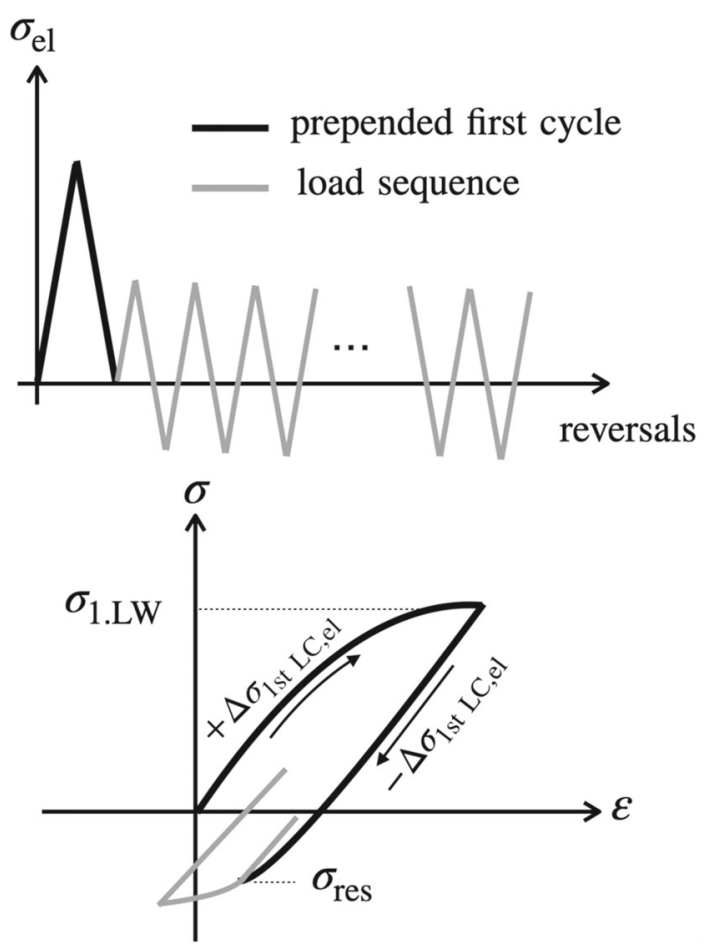

Fig. 4 Prepended load cycle (black) and load sequence (grey). In the lower figure, the corresponding stress-strain path is shown

\section{Consideration of the forming process in the fatigue life calculation}

In [14], the influence of residual stresses on fatigue life has already been investigated and combined with a transient material model. The transient material behaviour was characterized by experimental results from an incremental step test (IST). Since the IST is only carried out experimentally up to a maximum strain of $0.65 \%$, high residual stresses in forming processes cannot be considered. For this reason, a transient approach has to be introduced which describes a transition from the monotonic flow curve to the stabilized stress-strain curve obtained from the IST as a function of the damage variable $D$. Furthermore, the residual stresses of a forming process result from an loading-unloading process while the model in [14] considers residual stresses as pre-stresses which neglects the unloading scenario. For this reason, this paper considers an approach to model the residual stresses by prepending an additional loading cycle ahead of the fatigue life calculation.

\subsection{Consideration of residual stresses}

The application of residual stresses is achieved by prepending an additional loading cycle, see Fig. 4 (top). If the residual stresses $\sigma_{\text {res }}$ are known, e.g. from a elastic-plastic forming simulation, the amplitude of the elastic stress $\sigma_{1 \mathrm{st}} \mathrm{LC}$,el for the additional loading cycle is a value to be determined.

To apply an elastic-plastic stress-strain state with a compressive residual stress state $\sigma_{\text {Res }}<0$ at the beginning of the loading history, a loading cycle with stress ratio $R=0$ has to be determined with an elastic maximum stress $\sigma_{1 \mathrm{stLC} \text {,el }}$. Applying Neuber's rule, $\sigma_{1 \mathrm{stLC} \text {,el }}$ results in an elastic-plastic calculated stress $\sigma_{1 \mathrm{stLC}}$, see Fig. 4 (bottom). The residual stress $\sigma_{\text {Res }}$ from an elastic-plastic forming simulation is used as a scalar value which remains in the material after a first loading cycle. In an iteration using the LSA, different constant amplitude loading sequences need to be calculated in order to find $\sigma_{1 \mathrm{stLC}, \mathrm{el}}$.

After inserting this first load cycle to consider the residual stresses, the load sequence is processed reversal by reversal. In order to establish a continuous transition of the stress-strain curve from monotonic to cyclic material behaviour, the monotonic flow curve must be fitted with the parameters $K_{\text {stat }}^{\prime}$ and $n_{\text {stat }}^{\prime}$ according to (1) in addition to the CSSC. 

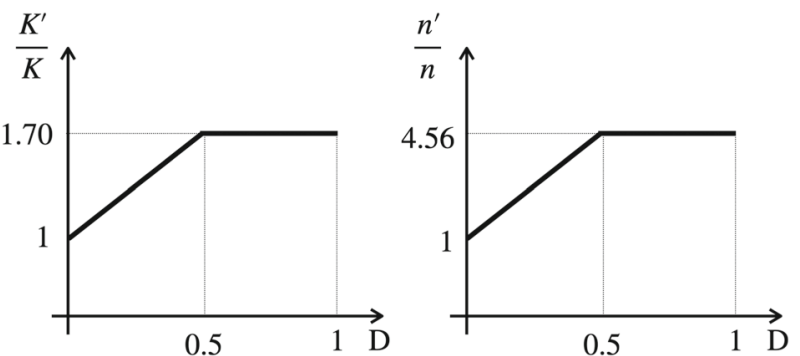

Fig. 5 Approach for modelling of the cyclic material parameters via the damage

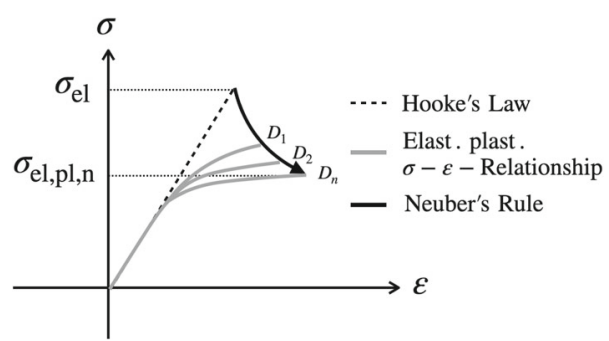

Fig. 6 Visualization of cyclic transient Neuber revaluation as an enhancement to the cyclic stabilized Neuber revaluation (see Fig. 3)

\subsection{Transient material behaviour}

In addition to residual stresses, cyclic hardening of the material is an important factor for the fatigue life of formed components. The application of the LSA as described in [26] uses the cyclically stabilized stress-strain curve, which neglects the transient material behaviour.

This paper presents a methodology which can be added to the LSA to consider transient material behaviour by a change in the stress-strain curves.

From a continuum mechanics point of view, the transient material behaviour and thus the change in the cyclic stress-strain curve are accompanied by the accumulated plastic strain. Since there is a connection between the accumulated plastic strain and the damage $D$, which is an already existing variable in the LSA, the transient change of the cyclic stress-strain curve is modelled as a function of the damage. In order to understand the development of the new concept, only the effects resulting from plasticity, which contribute to damage, will be considered here. Other effects, like surface roughness, statistical size effects or manufacturing caused imperfections, will not be discussed here.

To model the transition from the static to the cyclic stress-strain curve, a linear transition from the static flow curve to the cyclic stress-strain curve is assumed. The basic assumption, experimentally proven in [27], is that the material has reached the cyclic stabilized state at half of its fatigue life, see Fig. 5. Within the scope of the proposed extension to the LSA, equation (1) is adjusted with damage-dependent material parameters $K^{\prime}(D)$ and $n^{\prime}(D)$, see Fig. 6, resulting in lower stresses and higher strains (in case of cyclic material softening). Figure 7 shows schematically the damage dependence of the cyclic material behaviour during a loading sequence. The damage-dependent material behaviour changes the hysteresis loops in their orientation and slope during the loading sequence.

\subsection{Algorithmic implementation}

Figure 8 shows the necessary extension in order to consider transient material behaviour within the LSA. For each reversal point of the loading sequence, the local stress-strain path is simulated and the HCM distinguishes between a) a reversal point that leads to a closed hysteresis or b) a reversal point that is on either a non-closeable path or a not-yet-closed hysteresis branch. Reversal points of case b) are defined as residuum. After each reversal point, the damage sum $D$ is calculated. An update of Eqs. (3) and (1) was not carried out at every reversal point for reasons of computational efficiency. Instead, the stress-strain curves were stored as piecewise multilinear interpolation functions with a sufficiently large number of data points. Furthermore, the update of the CSSC 


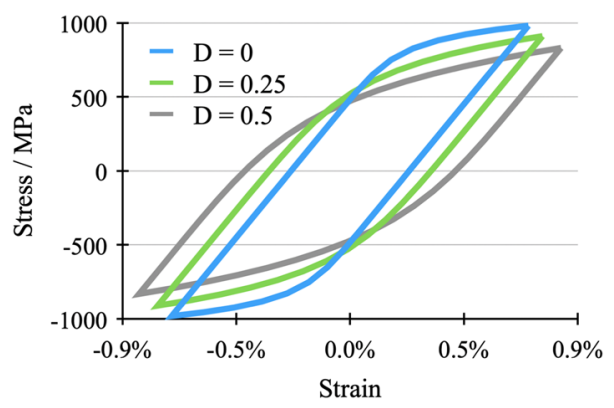

Fig. 7 Hystereses resulting from the modelling of cyclic transient material behaviour

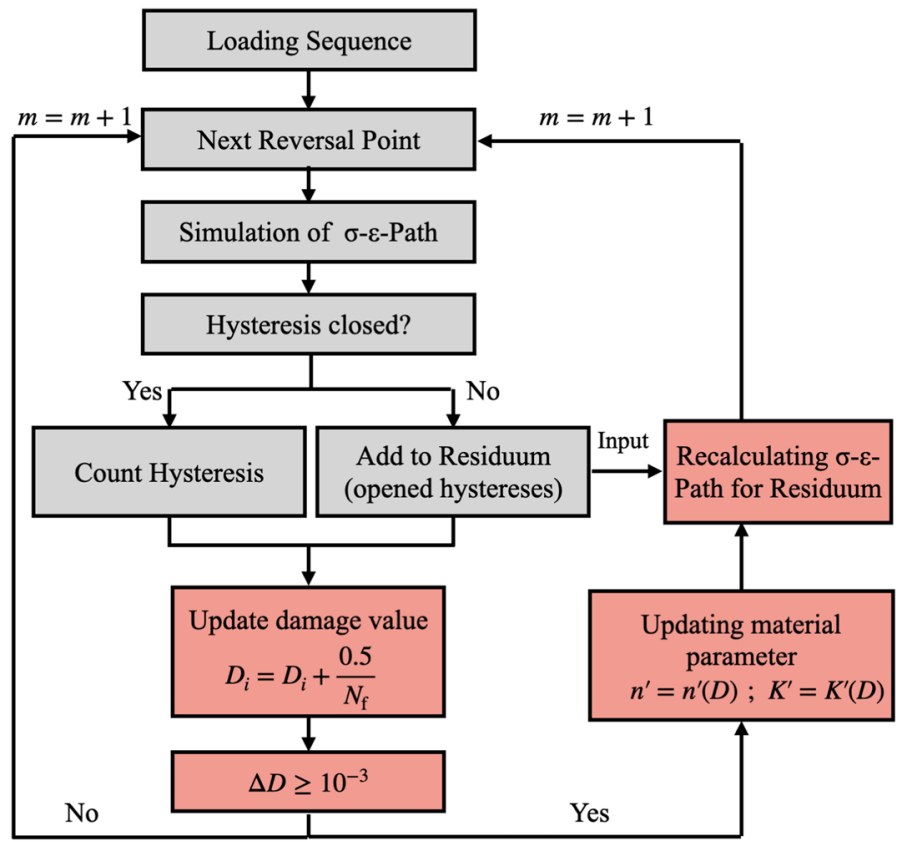

Fig. 8 Simulation of the local stress-strain path for an applied loading sequence. Red: Extension to the simulation procedure in order to consider transient material behaviour

is performed here at a specified damage increase of $\Delta D=10^{-3}$. Therefore, after each reversal point the damage increase is checked, and for a damage change $D \geq 10^{-3}$, the material behaviour changes. In order to consider the transient material behaviour and therefore the location of the hysteresis loops correctly, the counted residuum is simulated with the updated material parameters $K^{\prime}(D)$ and $n^{\prime}(D)$. Then the next reversal point is simulated. Using this methodology even with transient material behaviour, closed hysteresis loops are achieved. The damage sum is calculated after each reversal point with

$$
D_{n}=\sum_{n=1}^{N_{\text {Reversals }}} \frac{0.5}{N_{\mathrm{f}, i}} .
$$

The recalculation of the residuum with the new material parameters leads to no error in the damage sum and therefore in the fatigue life calculation. If a hysteresis branch is extended, for example after a memory 1 or 2 effect, the damage contribution of this branch is updated, see Fig. 9.

\section{Results and discussion}

In this section, the proposed addition to the LSA to consider residual stresses and transient material behaviour due to a forming process are validated for specimens of $42 \mathrm{CrMo} 4$. First, the influence of residual stresses and 

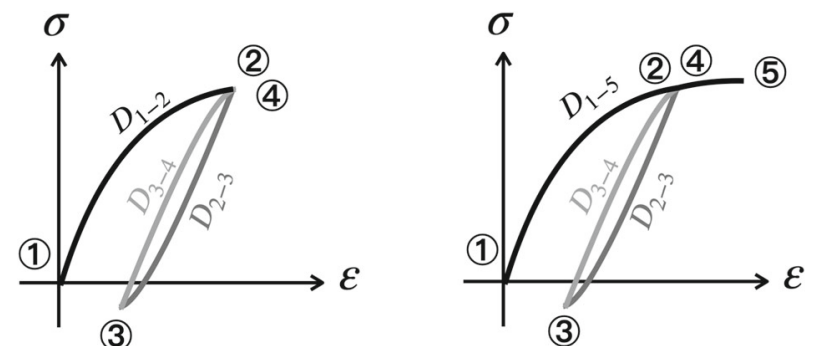

Fig. 9 Partial damages during step by step processing series of reversal points. Each half-cycle is associated with a damage value

Table 1 Material properties from IST

\begin{tabular}{llll}
\hline & First Cycle & Cyclic stabilized \\
\hline$K$ & 1308.70 & $K^{\prime}$ & 2227.89 \\
$n$ & 0.0475 & $n^{\prime}$ & 0.2168 \\
\hline
\end{tabular}

Table 2 Material properties from CA testing

\begin{tabular}{llll}
\hline$\sigma_{\mathrm{f}}^{\prime} / \mathrm{MPa}$ & $\varepsilon_{\mathrm{f}}^{\prime}$ & $b$ & $c$ \\
\hline 1502.3 & -0.0862 & 0.1319 & -0.45132 \\
\hline
\end{tabular}

the transient material behaviour on the local stress-strain path in the notch and on the fatigue life calculation are described in Sect. 4.2. To demonstrate the fatigue life analysis workflow using a real component, a forming simulation is performed for a skew rolled shaft. The residual stresses obtained from the process simulation are used as input data for the fatigue life simulation. Furthermore, the stress state of the rolled component is determined with a unit load simulation. Equivalent stresses are used as input data for the fatigue analysis. The influence of the residual stresses and transient material behaviour on the fatigue life calculation is demonstrated.

\subsection{Cyclic material characterization}

For the cyclic material characterization, a strain-controlled IST [15,25] and strain-controlled constant amplitude tests (CA) $[5,16,21]$ were performed with unnotched specimens of rolled $42 \mathrm{CrMo} 4$. The material parameters for the first loading cycle are derived from the static flow curve. Tables 1 and 2 show the determined material parameters.

\subsection{Influence of residual stresses on the fatigue life}

Figure 10 shows the influence of the residual stresses, included as a first loading cycle, on the local stressstrain path in the notch. For all stress-strain paths, the same constant amplitude loading sequence $(R=-1$, $S_{a}=500 \mathrm{MPa}$ ) was simulated after the residual stress cycle. The figure shows the differences between the simulated closed hysteresis loops of the constant amplitude sequence depending on the value of the residual stresses. For tensile residual stresses, the constant amplitude loading results in closed hysteresis loops with positive mean stresses, and compressive residual stresses lead to negative mean stresses.

Figure 10 shows the stress-strain answer of the prepended load cycle, resulting from the introduced residual stress. If multiple cycles are now simulated, residual stress-dependent Wöhler curves, see Fig. 11, are obtained. Above all, the increasing fatigue life with increasing compressive residual stress (negative sign) can be seen as well as the decreasing fatigue life with increasing tensile residual stresses. 


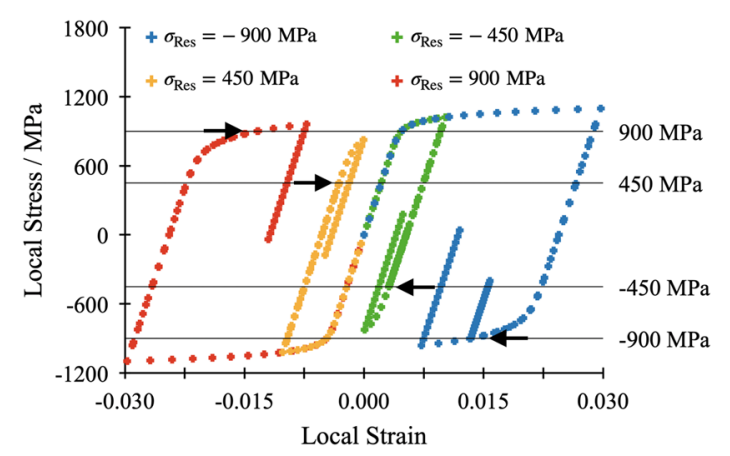

Fig. 10 Simulations of the elastic-plastic stress-strain path in the notch with different values of residual stresses for the same constant amplitude loading sequence $\left(R=-1, S_{\mathrm{a}}=500 \mathrm{MPa}\right)$. The black arrows indicate the residual stress level and starting point of the load sequence

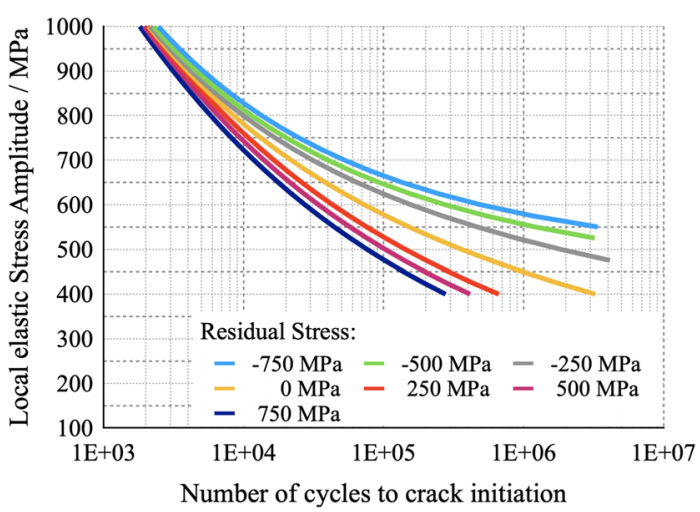

Fig. 11 Set of simulated Wöhler curves $\left(K_{\mathrm{t}} \approx 1\right)$ for different amounts of residual stresses

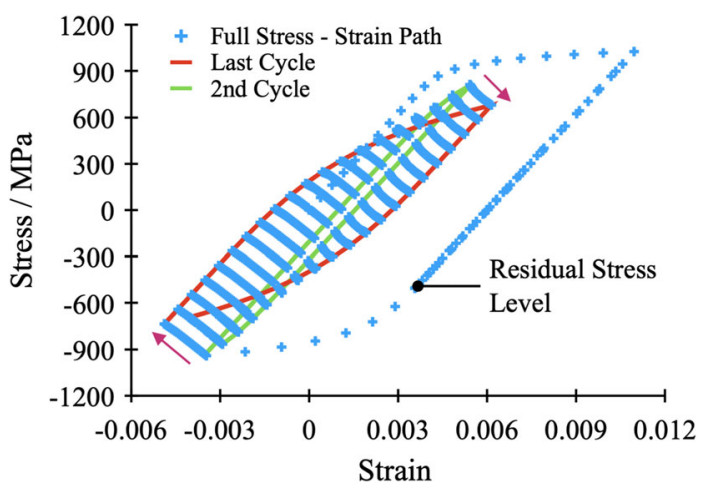

Fig. 12 Influence of transient material behaviour to the stress-strain path of a constant amplitude loading. Comparison of the 2nd closed hysteresis loop (with $K, n$ ) to the last closed hysteresis loop (with $K^{\prime}, n^{\prime}$ )

\subsection{Demonstration of cyclic stabilization}

Figure 12 shows the stress-strain path of a component under constant amplitude loadings with an additional residual stress cycle. The residual stress introduced here is $-500 \mathrm{MPa}$. Characteristic is the shift of the hysteresis curves with increasing damage. The arrows indicate the direction of the hysteresis shift, resulting from the damage-dependent change of the cyclic material parameters $K^{\prime}$ and $n^{\prime}$. 


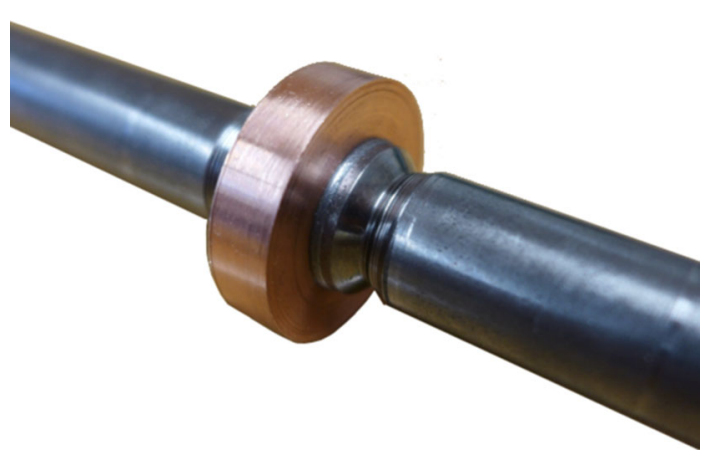

Fig. 13 Investigated skew rolled component (progressive manufacturing, $K_{\mathrm{t}}=3.6$ )

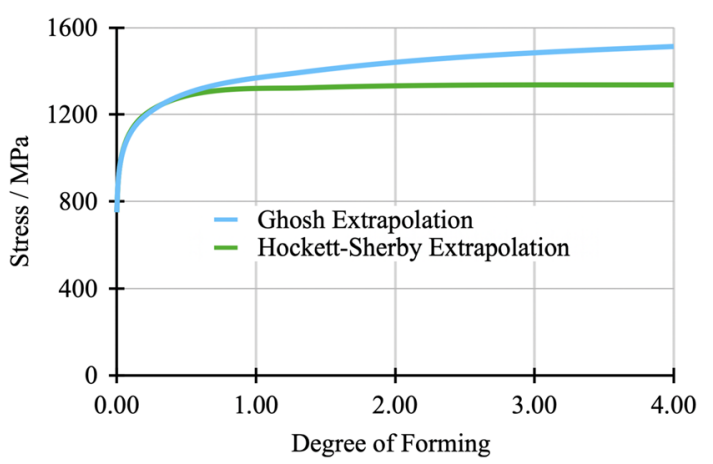

Fig. 14 Comparison of extrapolation approaches of flow curves according to Hockett-Sherby and Ghosh

\subsection{Process simulation of the skew rolled component}

The simulation of the forming process of a skew rolled component (see Fig. 13) has been carried out utilizing LS-Dyna R11.1.0 in an axisymmetric 2D model with an implicit solver. With the simplifying assumption of rotational symmetry of the workpiece, the rolling process is modelled as a circumferential indentation, thus neglecting any effects of pointwise loading on the material through rotational motion of the forming tools. This approach might lead to deviations in geometry compared to a manufactured component. However, it is assumed that those deviations are negligible with respect to the presented scope of research. The elastic-plastic material behaviour is approximated with a piecewise linear flow curve, combined with an isotropic hardening law and a von Mises yield surface. The flow curve of $42 \mathrm{CrMo} 4$ steel was acquired in a compression test, with Young's modulus determined at $210 \mathrm{GPa}$ and yield stress at $750 \mathrm{MPa}$, respectively. Two extrapolation approaches, according to Hockett-Sherby [12] as well as Ghosh [10], were employed to estimate stresses at larger strains, see Fig. 14.

The forming tool is modelled as a rigid body. The element size was set to $0.075 \mathrm{~mm}$ with $r$-adaptive mesh refinement to capture the tool geometry with small radius at the tip of the forming tool and handle large distortions. The static coefficient of friction is assumed at 0.1 . In addition, to limit the friction force to a maximum, a coefficient of viscous friction with a value of $433 \mathrm{MPa}$ is applied. To study the impact of residual stresses on fatigue life due to alternating forming processes, two different work roll paths are simulated in this paper. The progressive roll path finishes mainly with a radial motion. In case of the degressive roll path, the forming tool moves predominantly along the rotational axis. Both work roll paths as well as the geometrical features of the forming tool are presented in Fig. 15.

The distribution of residual stresses of both the progressive and degressive roll path after release of the forming tool is illustrated in Fig. 16 using the extrapolation approach according to Hockett-Sherby. As the von Mises stress is positive at all times, a suitable criterion is necessary to determine whether tensile or compressive residual stresses remain within the component. Options to consider are the sign of the maximum absolute principal stress or the hydrostatic stress. However, as the component considered in the following numerical example is being loaded axially, it is reasonable to assume that fatigue life is mainly, but not exclusively, affected by residual stresses in the direction of loading. Comparing the distribution of axial stresses in Fig. 


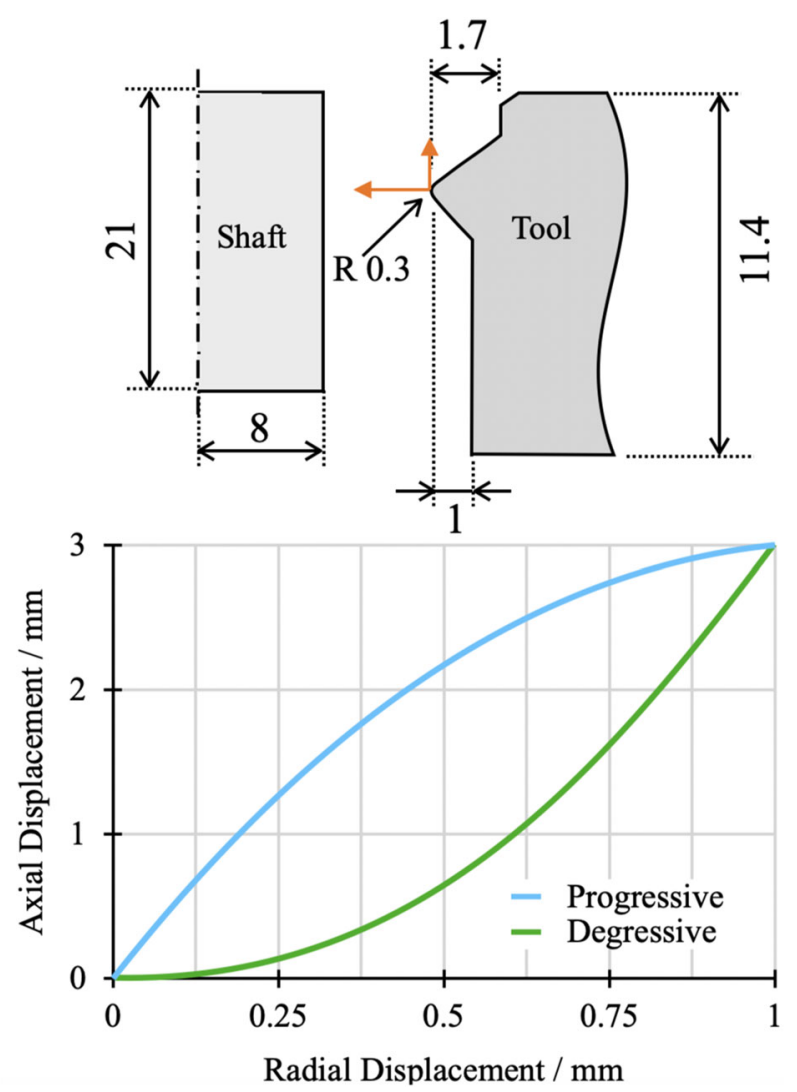

Fig. 15 Forming tool geometry (units in $\mathrm{mm}$, figure not to scale) with progressive and degressive work roll paths
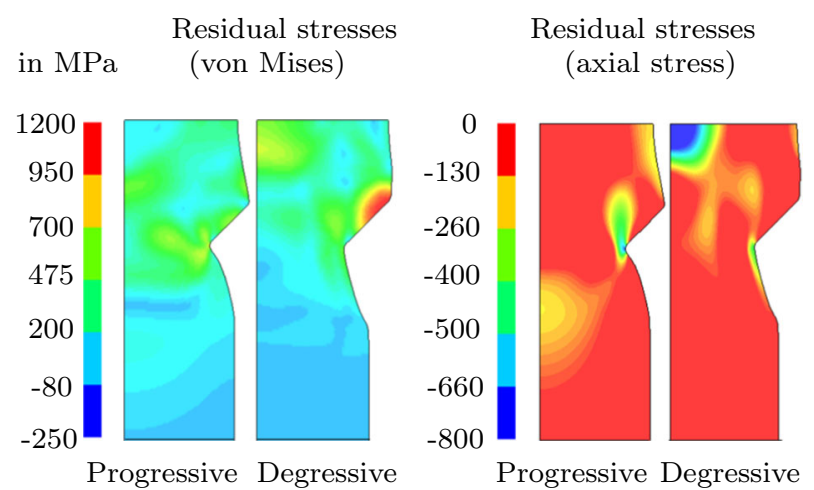

Fig. 16 Distribution of residual stresses for different work roll paths (flow curve approximation according to Hockett-Sherby)

16, it can be deduced that the progressive work roll path results in higher compressive stresses at the notch root. Furthermore, the area with compressive stresses around the notch is significantly bigger, which may contribute to fatigue crack growth retardation and crack arrest. A complementary process simulation with a flow curve extrapolation according to Ghosh had been carried out as well, although for brevity not presented here separately. Comparing the process simulation results, it was found that both extrapolation approaches yield similar distribution of stresses and final geometry. Of greater interest are the compressive stresses at the tip of the notch in case of the progressive work roll path. Simulation with a degressive work roll path, on the other hand, shows higher tensile stresses at the upper flank of the indentation. 
Fatigue Lives

(residual stress free)

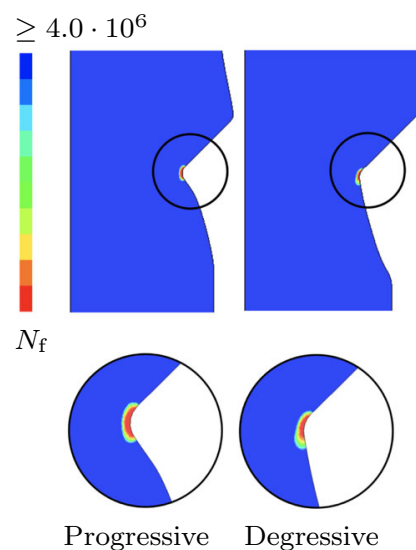

Fatigue Lives

(incl. residual stresses)
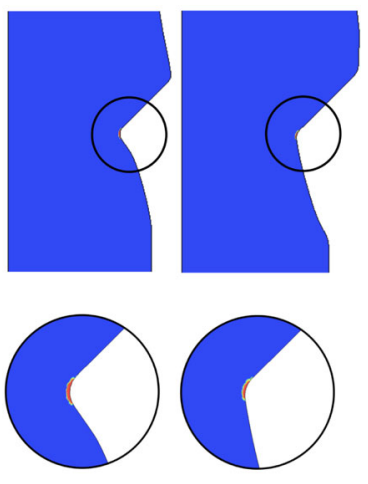

Progressive

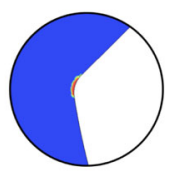

Degressive

Fig. 17 For the residual stress-free life cycle analysis, it is shown that a wider range becomes critical for failure. To show the effect, an arbitrary nominal stress was chosen as an example

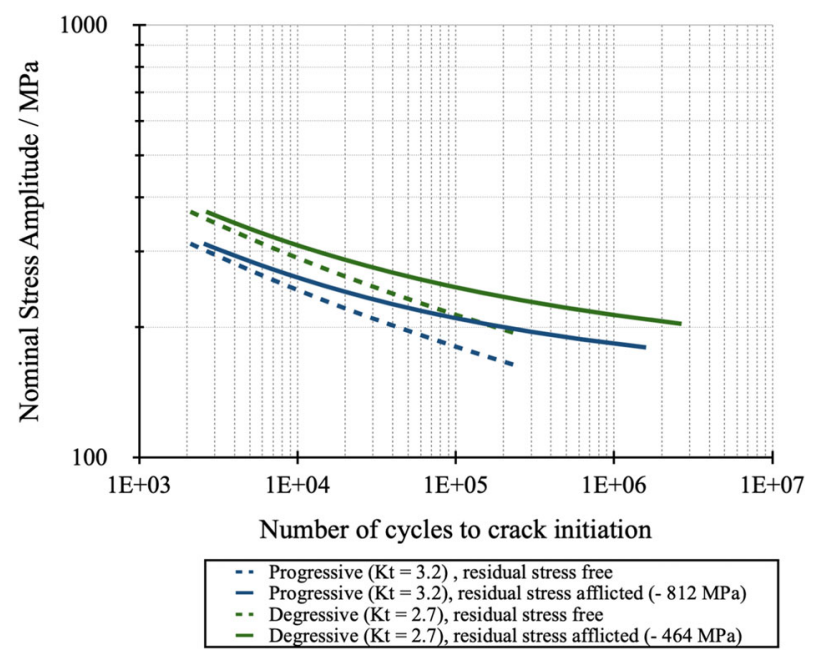

Fig. 18 Calculated Wöhler curves for crack initiation. The influence of residual stresses to the fatigue life is clearly visible

\subsection{Application of the extended LSA on the skew rolled component}

To determine $K_{\mathrm{t}}$, a subsequent loading simulation with components free of residual stresses is performed. With a small tensile force applied, $K_{\mathrm{t}}$ is calculated with 3.2 for progressive and 2.7 for degressive work roll path. Comparative analyses revealed that the choice of extrapolation approach has a negligible effect on the elastic stress concentration factor $K_{\mathrm{t}}$.

With the application of fatigue analysis as a continuum approach, the failure critical location can now be estimated (see Fig. 17). As the material point with the lowest number of cycles to failure $N_{f}$ that results from the superposition of the residual stress and the elastic notch stress.

In order to evaluate the influence of residual stresses on the fatigue life, progressively and degressively manufactured components are subjected to a specific load. This resulted in an axial stress of $-812 \mathrm{MPa}$ in the notch area of the progressively manufactured component and an axial stress of $-464 \mathrm{MPa}$ in the degressively manufactured variant. However, for the degressively manufactured variant, the highest equivalent stress is not located at the notch tip. The fatigue lives determined for this load were with consideration of the residual stresses, respectively.

The results are shown in Fig. 18. On the one hand, the notch effect of the component can be seen. The residual stress-free fatigue lives of the unnotched specimens differ in that the fatigue lives for $K_{\mathrm{t}}=2.7$ are higher than those for $K_{\mathrm{t}}=3.2$. Furthermore, it can be seen that the compressive residual stress-affected 


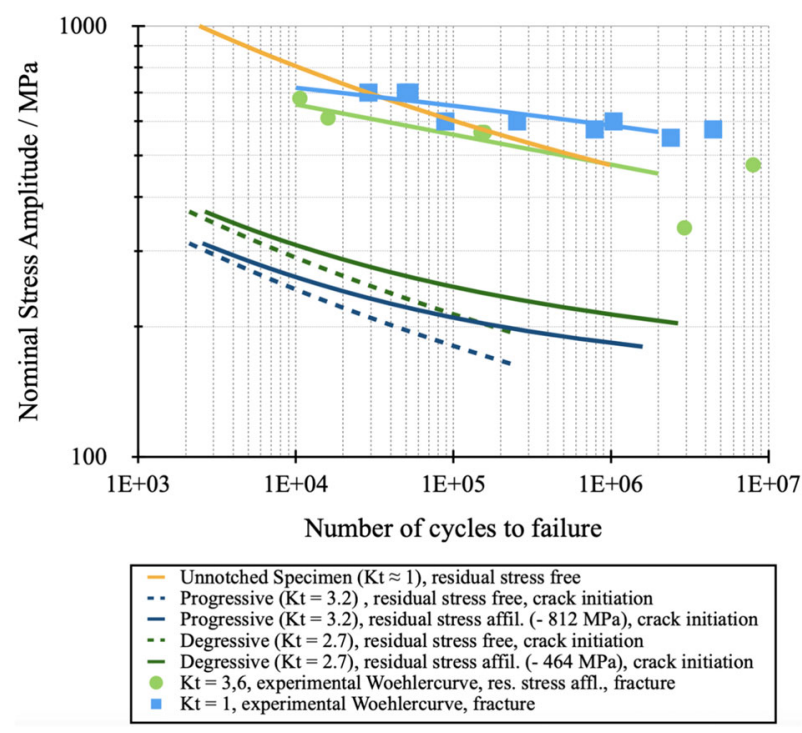

Fig. 19 Calculated Wöhler curves for crack initiation in comparison with the Wöhler curves of Fig. 1 for fracture. The influence of residual stresses to the fatigue life is clearly visible

notched specimens have higher fatigue lives than the residual stress-free notched specimens. Especially at lower load amplitudes, a significant increase in fatigue life can be seen. The influence of the extrapolation approaches is marginal in terms of fatigue life.

In order for the concept to serve as an estimation concept later on, a validation must be carried out on the component. The number of load cycles determined for the component so far has only been used to estimate the tendency of the component's fatigue life under consideration of the residual stresses. In order to be able to make valid statements on the fatigue life as a general estimation concept, further influences must be taken into account.

\section{Conclusions}

This paper presents an approach to consider residual stresses, and transient material behaviour in a fatigue life calculation within the local strain approach (LSA). The residual stresses were taken into account by an additional loading cycle, and the results for the local stress-strain path in the notch were shown. A simple method to simulate transient material behaviour from the static to the cyclic stabilized stress-strain curve was introduced which is able to consider high strains due to forming processes. For a skew rolled component of $42 \mathrm{CrMo} 4$, a process simulation was performed in order to investigate residual stresses. Based on the new approach to consider residual stresses and transient material behaviour, see Fig. 19, fatigue life calculations with the LSA for crack initiation shows a conservative fatigue life estimation in comparison with experimental fatigue lives for fracture. These results are in accordance to researches by Altenberger [1], who notes that the positive effects of deep rolling on the fatigue life of notched specimen will mostly occur in the crack propagation process. Due to the similarities in skew rolling and deep rolling, a similar behaviour can be expected here. Furthermore, the calculated Wöhler curve for the unnotched specimen is represented here.

In order to be able to ensure a better estimation accuracy, further experimental investigations must be carried out.

As a first approach, the transient material behaviour in the current research project only takes into account the damage-dependent change in shape and rotation of the hystereses, which are also experimentally detectable in incremental step tests. Further transient effects such as cyclic mean stress relaxation or cyclic creep are not yet described here by the current material model. For this purpose, further extensions of the approach with their corresponding parameters have to be implemented and experimentally calibrated. Experimental data describing this effect are not yet available for the material considered here.

As has been proved experimentally in [19,23], the cyclic material properties of steel alloys can be altered significantly due to large deformation. Currently the challenges lie in manufacturing proper test specimens with 
comparable degree of deformation as the skew rolled component that has been discussed in the paper at hand. Though methods exist to estimate cyclic properties either from hardness measurements [30] or from degree of deformation [17], the influence of forming on material properties is still an aspect of ongoing research. Based on these investigations, further parameters for the modification of the concept can be identified, and finally, the transferability to the real component can be established.

Acknowledgements This work was funded by the Deutsche Forschungsgemeinschaft (DFG, German Research Foundation) in the Priority Program 2013 Targeted Use of Forming Induced Residual Stresses in Metal Components (Grant Numbers KA 3309/7-2 and BR 3500/21-2).

Open Access This article is licensed under a Creative Commons Attribution 4.0 International License, which permits use, sharing, adaptation, distribution and reproduction in any medium or format, as long as you give appropriate credit to the original author(s) and the source, provide a link to the Creative Commons licence, and indicate if changes were made. The images or other third party material in this article are included in the article's Creative Commons licence, unless indicated otherwise in a credit line to the material. If material is not included in the article's Creative Commons licence and your intended use is not permitted by statutory regulation or exceeds the permitted use, you will need to obtain permission directly from the copyright holder. To view a copy of this licence, visit http://creativecommons.org/licenses/by/4.0/.

Funding Open Access funding enabled and organized by Projekt DEAL.

\section{Declaration}

Conflict of interest The authors declare that they have no conflict of interest.

\section{References}

1. Altenberger, I.: Deep rolling-the past, the present and the future. Conf. Proc.: ICSP 9, 144-155 (2005)

2. Bland, R., Putnam, A., Miner, M.: Cumulative damage in fatigue. J. Appl. Mech.-Trans. ASME 13(2), A169-A171 (1946)

3. Blasón, S., Rodríguez, C., Belzunce, J., Suárez, C.: Fatigue behaviour improvement on notched specimens of two different steels through deep rolling, a surface cold treatment. Theor. Appl. Fracture Mech. 92, 223-228 (2017)

4. Clormann, U.H., Seeger, T.: HCM - Ein Zählverfahren für Betriebsfestigkeit auf werkstoffmechanischer Grundlage. Stahlbau 55, (1986)

5. Coffin, J. L. F., U.S. Atomic Energy Commission., General Electric Company., \& Knolls Atomic Power Laboratory. A study of the effects of cyclic thermal stresses on a ductile metal (1963)

6. Dowling, N. E. (2003). Local Strain Approach to Fatigue. In Comprehensive Structural Integrity (pp. 77-94). Elsevier. https:// doi.org/10.1016/B0-08-043749-4/04031-3

7. Fiedler, M., Vormwald, M.: Berechnung von Anrisslebensdauern auf Basis des örtlichen Konzepts. Materialwissenschaft und Werkstofftechnik, 47(10), 887-896. (2016). https://doi.org/10.1002/mawe.201600616

8. Fiedler, M., Vormwald, M.: Introduction to the new fkm guideline which considers nonlinear material behaviour. In: MATEC Web of Conferences, vol. 165, article 10014. EDP Sciences (2018)

9. Fiedler, M., Wächter, M., Varfolomeev, I., Vormwald, M., Esderts, A.: FKM Richtlinie nichtlinear - Rechnerischer Festigkeitsnachweis für Maschinenbauteile unter expliziter Erfassung nichtlinearen Werkstoff-Verformungsverhaltens, vol. 1. VDMA-Verlag GmbH, Frankfurt (2019)

10. Ghosh, A.K.: A physically-based constitutive model for metal deformation. Acta Metallurgica 28, 1443-1465 (1980). https:// doi.org/10.1016/0001-6160(80)90046-2

11. Guilleaume, C., Brosius, A.: Simulation methods for skew rolling. Proc. Manufact. 27, 1-6 (2019)

12. Hockett, J.E., Sherby, O.: Large strain deformation of polycrystalline metals at low homologous temperatures. J. Mech. Phys. Solids 23, 87-98 (1975). https://doi.org/10.1016/0022-5096(75)90018-6

13. Kloos, K.: Größeneinfluss. Einfluss der Probengrößeauf das Ermüdungsverhalten bauteilähnlicher Kerbproben unter einstufigen und zufallsartigen Beanspruchungsabläufen). Abschlussbericht Vorhaben Nr. 145-2, Forschungskuratorium Maschinenbau e.V., Heft 192 (1995)

14. Kühne, D., Guilleaume, C., Seiler, M., Hantschke, P., Ellmer, F., Linse, T., Brosius, A., \& Kästner, M. (2018). Fatigue analysis of rolled components considering transient cyclic material behaviour and residual stresses. Production Engineering, 13(2), 189-200. https://doi.org/10.1007/s11740-018-0861-9

15. Landgraf, R.: Determination of the cyclic stress-strain curve. J. Mater. 4(1), 176-188 (1969)

16. Manson, S.S.: Fatigue: A complex subject-some simple approximations. Exp. Mech. 5(4), 193-226 (1965). https://doi.org/ $10.1007 / \mathrm{bf02321056}$

17. Masendrof, R.: Einfluss der umformung auf die zyklischen werkstoffkennwerte von feinblech. dissertation, Technische Universität Claustahl (2001)

18. Masing, G.: Eigenspannungen und Verfestigung beim Messing. pp. 332-335, Proceeding of the 2nd International Congress of Applied Mechanics, Corfu, Greece (1926)

19. Medhurst, T., Suesse, D.: Nutzung des Leichtbaupotentials von höchstfesten Stahlfeinblechen durch die Berücksichtigung von Fertigungseinflüssen auf die Festigkeitseigenschaften, FAT-Schriftenreihe 242. VDA (2012)

20. Merkleina, M., Andreasa, K., \& Engela, U. (2011). Influence of machining process on residual stresses in the surface of cemented carbides. Procedia Engineering, 19, 252-257. https://doi.org/10.1016/j.proeng.2011.11.108 
21. Morrow, J.: Cyclic plastic strain energy and fatigue of metals. In: Internal Friction, Damping, and Cyclic Plasticity, pp. 45-45-43. ASTM International. https://doi.org/10.1520/stp43764s

22. Neuber, H.: Theory of stress concentration for shear-strained prismatical bodies with arbitrary nonlinear stress-strain law. J. Appl. Mech. 28(4), 544-550 (1961). https://doi.org/10.1115/1.3641780

23. Palma, V.D., Tomasella, A., Frendo, F., Melz, T., Sonsino, C.M.: Analysis of different fatigue damage accumulation theories and damage parameters based on experiments with the steel HC340la. Materialwissenschaft und Werkstofftechnik 47(12), 1160-1173 (2016). https://doi.org/10.1002/mawe.201600589

24. Palmgren, A.: Die Lebensdauer von Kugellargern. Zeitschrift des Vereines Deutscher Ingenieure 68(4), 339 (1924)

25. Prüf- und Dokumentationsrichtlinie für die experimentelle Ermittlung mechanischer Kennwerte von Feinblechen aus Stahl für die CAE-Berechnung: Testing and documentation guideline for the experimental determination of mechanical properties of steel sheets for CAE-calculations. Stahl-Eisen-Prüfblätter (SEP) des Stahlinstituts VDEh. Verlag Stahleisen (2006)

26. Radaj, D., Sonsino, C., Fricke, W.: Notch strain approach for seam-welded joints. In: Fatigue Assessment of Welded Joints by Local Approaches, pp. 191-232. Elsevier (2006). https://doi.org/10.1533/9781845691882.191

27. Ramberg, W., Osgood, W.R.: Investigation of stress-strain curves by three parameters (1943)

28. Reiss, A., Engel, U., Merklein, M.: Investigation on the influence of manufacturing parameters on the fatigue strength of components. Key Eng. Mater. 554-557, 280-286 (2013). https://doi.org/10.4028/www.scientific.net/kem.554-557.280

29. Rennert R, Kullig E, Vormwald M, Esderts A, Siegele D (2012) FKM Richtlinie - Rechnerischer Festigkeitsnachweis für Maschinenbauteile aus Stahl, Eisenguss- und Aluminiumwerkstoffen. 6th revised edition; Editor: Forschungskuratorium Maschinenbau (FKM), Frankfurt / Main

30. Roessle, M.L., Fatemi, A.: Strain-controlled fatigue properties of steels and some simple approximations. Int. J. Fatigue 22, 495-511 (2000)

31. Smith, K., Topper, T., Watson, P.: A stress-strain function for the fatigue of metals (stress-strain function for metal fatigue including mean stress effect). J Mater. 5, 767-778 (1970)

32. Spaggiari, A., Castagnetti, D., Dragoni, E., Bulleri, S.: Fatigue life prediction of notched components: a comparison between the theory of critical distance and the classical stress-gradient approach. Proc. Eng. 10, 2755-2767 (2011)

33. Taddesse, A. T., Zhu, S.-P., Liao, D., \& Keshtegar, B. (2020). Cyclic plastic zone-based notch analysis and damage evolution model for fatigue life prediction of metals. Materials \& Design, 191, 108639. https://doi.org/10.1016/j.matdes.2020.108639

34. Trauth, D., Klocke, F., Mattfeld, P., Klink, A.: Time-efficient prediction of the surface layer state after deep rolling using similarity mechanics approach. Proc. CIRP 9, 29-34 (2013)

35. Wächter, M.: Zur Ermittlung von zyklischen Werkstoffkennwerten und Schädigungsparameterwöhlerlinien. Technische Universität Clausthal (2016)

36. Zhu, S.P., He, J.C., Liao, D., Wang, Q., Liu, Y.: The effect of notch size on critical distance and fatigue life predictions. Mater. Des. 196, 109095 (2020)

Publisher's Note Springer Nature remains neutral with regard to jurisdictional claims in published maps and institutional affiliations. 